\title{
THE APOTHEGARIES OF THE GENERAL INFIRMARY AT LEEDS
}

\author{
by \\ S. T. ANNING
}

On 20 May 1767 , a meeting was held at the New Inn at Leeds to 'consider of the Expediency of an Infirmary'. It was unanimously agreed 'That a Parochial Infirmary in this Place will be of great Utility'. At a meeting in June it was further agreed that the proposed infirmary should serve not only the parish of Leeds but 'that the Infirmary intended to be erected be declared a General One' and it was resolved 'That the said Infirmary be stiled, The General Infirmary at Leeds'.

In July (at the Old Kings Arms) it was agreed that:

Mr. Andrew Wilson's House . . . in Kirkgate . . . is deemed a proper place for a temporary Infirmary.

The house was opened for the reception of patients on 2 October 1767 at first with three in-patients but before long there were twelve. In December of that year a committee was considering sites on which to build the infirmary and on I March 1771 the new infirmary, built by John Carr in Infirmary Street on the site of the present Yorkshire Bank, was opened to receive twenty-seven inpatients (Fig. 1). By 1787 there were sixty-four beds, and in 1807 one hundred. On 24 February I860 there were one hundred and forty-three patients in the House.

A few weeks before the infirmary at Leeds was opened, on 14 August 1767 , William Thomas Trant aged 19 years was chosen for the office of apothecary at the salary of $£_{15}$ a year with board and lodging. Two candidates (the other being Benjamin Shepherd) had presented themselves before the Board in consequence of advertisements in the local papers. Trant was the first of a succession of twenty-five apothecaries who for nearly a hundred years played an important part in the work of the institution (Table I). In 1860 the title of the appointment was changed to Resident Medical Officer at the time that Thomas Richard Jessop, later father-in-law to the Ist Lord Moynihan of Leeds, was elected.

It is the purpose of this paper to attempt to provide some information about the qualifications, duties and later careers of the apothecaries of this hospital.

\section{Qualifications for the Office}

The apothecaries began in medieval times as itinerant medicine-sellers, and later settled in shops. In 1632 the College of Physicians obtained an order forbidding apothecaries to prescribe medicines, and until the Great Plague the 


\section{S. T. Anning}

physicians exercised almost a monopoly over the treatment of the sick. The physician wrote his 'bills', which the apothecary dispensed. During the plague the apothecaries remained at their shops when most of the physicians had left, and they visited the plague victims in their homes. Their right to treat the sick was established in the mind of the public. The apothecary was only allowed to charge for medicines supplied and not for his advice but in 1829 it was held that an apothecary might claim remuneration either for his medicines or for his skill and attention, but that he must not charge for both. In 1838 the right of the apothecary to claim payment for both medicine and advice was legally confirmed. ${ }^{1}$

The early apothecaries of the infirmary had no licences or diplomas. Membership of the Royal College of Surgeons of England was instituted in 1800 and the examination for the Licenciate of the Society of Apothecaries was ordered by the Apothecaries Act of 1815. W. T. Trant and his successors would have been apprentices seven or five years to an apothecary, but details are not available. William Carr (appointed in 1774) had been apprenticed to W. T. Trant but, as the latter had resigned in 1770, Carr cannot have been apprenticed four years unless he served with another master first. Mr. Trant was

paid Two Guineas as a Gratuity for the Attendance of his Apprentice as Apothecary to the Infirmary.

Thomas Rusby (appointed I79I) had been apprenticed to Mr. Oxley of Pontefract, Joseph Prince Garlick (appointed 1815) had been five years with his brother at the dispensary at Halifax, and Jessop (the first R.M.O.) had served five years' apprenticeship in Bradford.

When diplomas and licences became necessary for practice many of the apothecaries qualified after resigning their office though some obtained them while holding the appointment. J. P. Garlick (apothecary 1815-22) qualified M.R.C.S. Eng. and L.S.A. in 1817 . He had, in August 1816 , requested 'permission to attend the Lectures at London for completing his education' and this had been granted. When he resigned in 1822 the advertisement for his successor states that 'Candidates must have attended Lectures on Anatomy, Medicine and Surgery, and be free from the care of a family'. John Clayton Cooper (apothecary 1822-6) also qualified while he was apothecary, requesting in 1824 'permission of the Board to attend a Course of Lectures commencing January next'. It was granted and he became M.R.C.S. Eng. in May 1825 .

The first qualified apothecary to be appointed was Richard Farrer who had become M.R.C.S. and L.S.A. in 1826 just before he was elected. Thereafter all the apothecaries were qualified men.

The early advertisements for the office were placed in the Leeds papers (the Leeds Intelligencer, later the Yorkshire Post, and the Leeds Mercury) and once, in 1770, in the York Courant. The first reference in the Board minutes to advertising more widely was in 1852 when the following advertisement was ordered to be inserted in the Leeds papers and in the Lancet for an apothecary: 


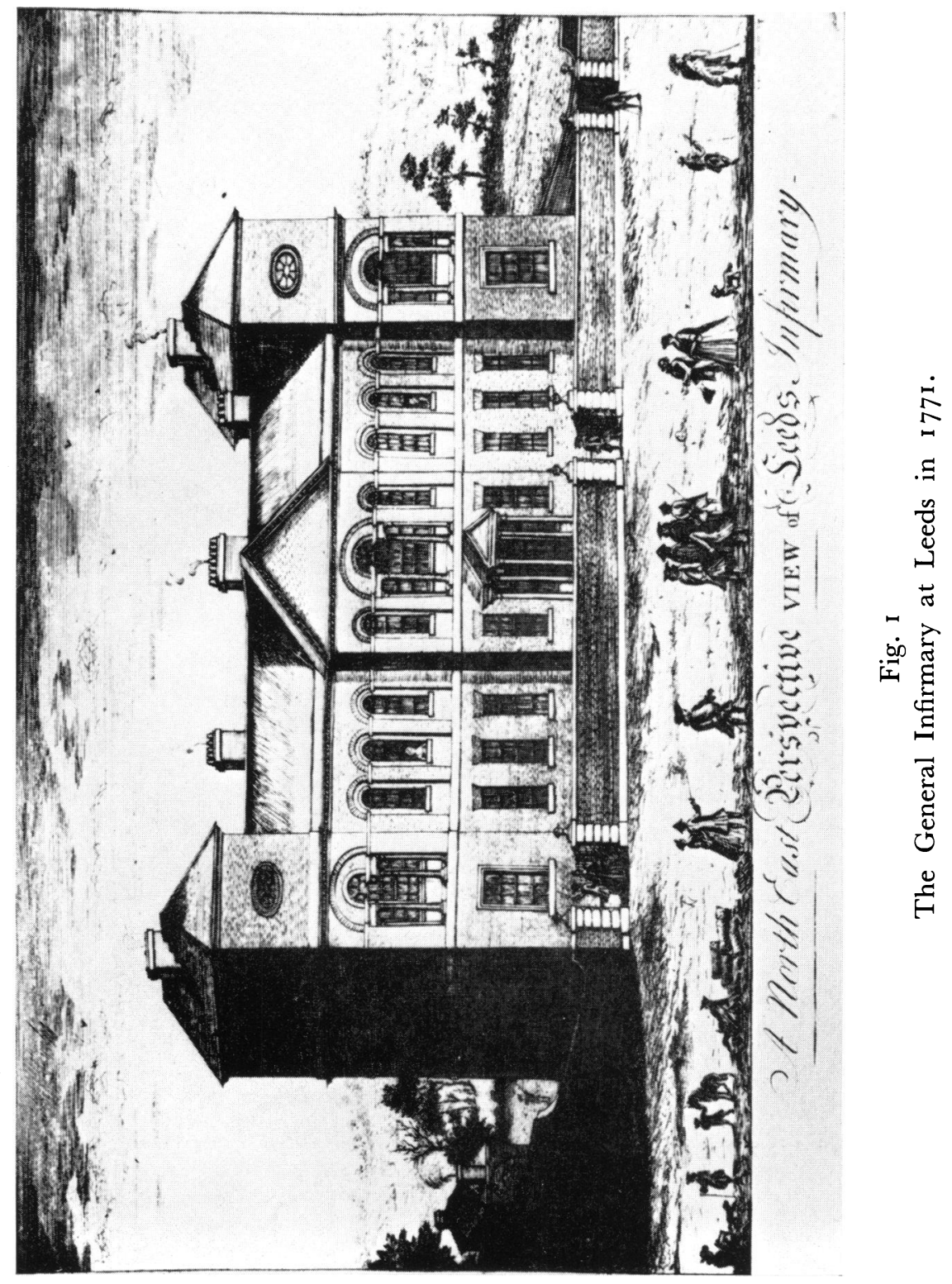




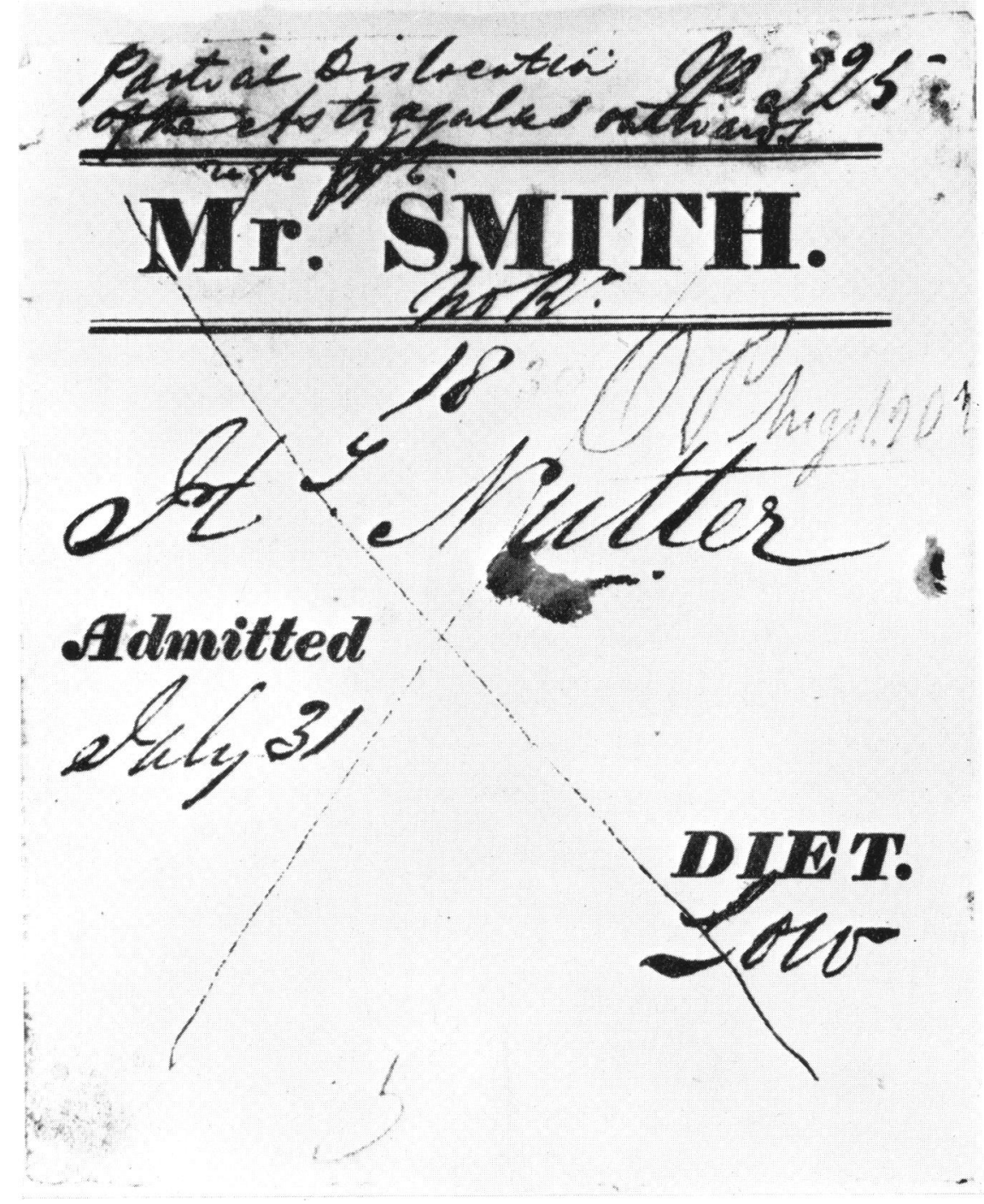

Fig. 2

A Bed Ticket. The patient, Henry Nutter, aged I8, was admitted on 31 July I83 I for 'partial dislocation of the astragalus outwards' and he was made an out-patient on 20 August. 


\section{The Apothecaries of the General Infirmary at Leeds}

Candidates must be Members of the Royal College of Surgeons, Licenciates of the Worshipful Company of Apothecaries and free from the care of a family. Salary $£ 100$ per Annum, with Board, Lodging and Washing. ....

The necessity for the apothecary to be free from the care of a family had been laid down in the Rules and Orders of $1767 . .^{2}$ The requirement as to age is referred to in the advertisement which appeared in the Leeds Intelligencer in December I 772, that 'an active Middle Aged Man is wanted as an Apothecary'. Mr. Abel Taylor was appointed having given his solemn promise that he would never set up as 'Surgeon, Apothecary or Druggist within this Parish'. His age is not mentioned but of the apothecaries whose age on appointment we know, most were in their twenties-Trant 19, Hardcastle 23, Rusby 28, Cass 21, Beckett 21, Garlick 23 and Allanson 29.

At first the apothecaries were appointed and re-appointed annually by the General Quarterly Board. All subscribers and the physicians and surgeons could attend and vote. At a special board held for the purpose of electing an apothecary in August 1810, ninety-five were present and there were eighty-four votes by proxy. It is curious that the number of subscribers attending the election of an apothecary was frequently much greater than those who voted for the election of a physician or surgeon.

In April 1813, at an election (on this occasion for an assistant apothecary), the gentlemen of the faculty were desired to withdraw and examine the candidates respecting their professional ability and it seems that the view that the physicians and surgeons were best qualified to choose an apothecary was becoming accepted. In January 18I5:

the Gentlemen of the faculty having been requested to consider of the best method of serving the Institution in the office of Apothecary have presented a statement of their opinion in which they propose That the appointment of Apothecary be vested in themselves and that a considerable Addition should be made to his Salary.

This was accepted by the Quarterly Board and from then the apothecary was chosen by 'the Physicians and Surgeons of ye Infirmary', and introduced to the members of the next Weekly Board by the senior physician or surgeon.

\section{The Duties of the Apothecary}

The Rules and Orders (July $\left.{ }_{7} 767\right)^{2}$ laid down the apothecary's duties:

That the Apothecary fix a Ticket on each Patient's Bed, specifying the Name of the Patient, together with that of the Physician or Surgeon, the Time of Admission, and also the Diet, according to the Prescription of the Physician or Surgeon; and that he give a List of the same to the Matron each prescribing Day.

Such a ticket made out for a patient admitted in 1831 is shown in Fig. 2.

That he visit the Wards every Morning, and be prepared to report the State of the Patients to the Physicians or Surgeons. That an Account of the Number of Beds, which become vacant 


\section{S. T. Anning}

in each Ward, be delivered by him at the Weekly Board [which met every Friday afternoon, even on Christmas day] with a List also of the Patients received into the House in the foregoing Week, and of such Patients as have been in the House two Months. That he dispense no Medicines, without the Direction of the Physicians or Surgeons, except in Cases of Necessity, when they cannot be consulted: that he do not presume to practice for himself, or attend any other Business than that of the Infirmary. ... That he never be absent when the Physicians and Surgeons are to attend; or during the absence of the Matron; that he always leave Notice with the Matron where he may be found; and in Case of Sickness, or other necessary Avocation, that he depute another Apothecary, who shall be approved of by the Physicians and Surgeons, to officiate in his Place.

In the Minute Books we find little evidence that these rules were disobeyed though in 1815 Mr. Garlick was reported for being absent before the Weekly Board had dissolved. An enquiry being made

on Mr. Garlick's absence and it appearing to the satisfaction of this Board that he had gone at the pressing request of an Outpatient whose situation was of so critical a nature as to require immediate attention, [it was resolved] that the thanks of this Board be given to Mr. Garlick for his active \& humane attentions upon that occasion.

\section{The Apothecary's Shop}

Annually the apothecary had to make an 'Inventory of the Shop goods, Utensils \& Surgeons' Instruments including Druggs' and to sign the same. A committee was appointed in 1770 for buying drugs but the apothecary was empowered to provide any that were necessary. It was ordered that

he deliver to the Weekly Board an Account of what Drugs are expended, and that he bring in a Bill of the Expence, at least once in every Month.

This bill for 'Apothecary's Incidents' was rarely stated in the minutes in detail and on the first occasion, in December 1849, it was as follows:

\begin{tabular}{lrrr} 
& $£$ & s & $d$ \\
Incidents & & 2 & 7 \\
Leeches & 6 & 19 & 3 \\
Letters \& Parcels & 15 & 2 \\
Instruments & I & 4 & 0 \\
Machines & 16 & 0 \\
Drugs & 1 & 4 & 5 \\
\hline & $£$ II & I & 5 \\
\hline
\end{tabular}

In the following February the amount spent on leeches had fallen to $£ 39 s .3 d$. The annual sums of the 'Apothecary's Incidents' varied between $£ 6$ in 1 771-2 and $£ 82$ in $1811-12$ and was usually about $£ 30$. The amount spent on leeches in $1821-2$ was $£ 58$.

The Apothecary's Shop was an important part of the institution but detailed information about it is meagre. In September I 773 a 'Drug Man' was appointed 


\section{The Apothecaries of the General Infirmary at Leeds}

at the salary of $£ 8$ a year, and from October 1778 this individual, who must have been of great assistance to the apothecary, was known as the 'Elaboratorian' and the Apothecary's Shop as the 'Elaboratory'. A marble mortar and a screw press were ordered for the latter in October 1778 , and in October 1802 it was ordered

That the pipe for soft water be brought into the shop, under the direction of ye Apothecary.

There was some friction between the apothecary and the elaboratorian when a minute records:

At this Board the Apothecary of the Infirmary [Thomas Rusby] accused his Man of secreting a quart of Beer with Intent to give it to 2 Patients who had been assisting him in making Pills he also accused him of speaking Words disrespectful to Himself-The Defendant allowed the Facts and in his turn accused the Apothecary of Negligence in his Duty saying that since the present Apothecary Mr. Rusby came he had done both his own Work \& his he moreover accused him of receiving a Gallon of Wine as a Bribe from Messers Spencer \& Sons Druggists that he might favour them with Orders to the prejudice of the rest in that Trade. Ordered: That the Apothecary's Man be discharged in a Fortnight.

The elaboratorian was usually chosen by the Board after an advertisement inserted in the Leeds paper but in June 1800 the Weekly Board ordered 'that Mr. Cass [the apothecary] do provide an Elaboratorian. ...' The title of the post was changed in 1845 following

an Advertisement in the Newspapers for a Candidate to supply the Vacancy of Elaboratorian, occasion'd by the resignation of Joseph Kenyon, there were nine Candidates attended with respectable Testimonials for each. When the Board elected Luke Turton to the vacant Office who had been for two Years acting as Dispenser at the Dispensary in North Street.

The Leeds Public Dispensary was opened in 1824 .

In May 1845 Mr. Allanson, the apothecary, made application to the Weekly Board for the painting of the Apothecary's Shop, stating that it was in a dirty state and

that the Labels on the front of the Drawers \& Bottles, in consequence of the recent changes in the names of many of the Chemicals, \& an entire alteration in the Medical prescriptions, that nearly one half of them are rendered quite useless. It was Resolved-That Mr. Kershaw do paint the Shop etc. according to the above Estimate, the labeling the Drawers \& Bottles to be under Mr. Allanson's direction.

The amount of money spent on drugs was carefully watched by the Quarterly Board which in 1799 ordered a gratuity of ten guineas to Anthony Cass, apothecary, 'for good conduct and for his Economy in the management of Drugs'. For several years more than $£ 500$ had been spent annually on drugs but in $1797-8$ the cost had dropped to $£ 417$ and in $179^{8-9}$ to $£ 337$ although the number of patients treated during these years was about the same (approximately 920 in-patients and 1,310 out-patients). 


\section{S. T. Anning}

Mr. W. T. Trant (the first apothecary) had settled in Leeds as a druggist and supplied some of the Infirmary's requirements. He was paid $f^{8}$ is. od. for drugs supplied from April to September 1785 and larger amounts varying from $£ 30$ to $£ 92$ in the years $1789-92$. In 1787 his 'bill for druggs' was queried but paid a year later $\left(£ 4^{2} 3^{s} .3 \frac{1}{2} d.\right)$. His bills were carefully scrutinized and in September 1794 the Board ordered 'that Mr. Trant be desired to send another Bill specifying the Particulars of Quantity \& Price'. He was still in business in 1826 .

The Weekly Board ordered in 1813

that with a view to prevent the great waste of Bottles \& Gally pots by the Patients not returning them, That every Patient do deposit the price of them with the Apothecary which shall be refunded when the Patient shall return the said Bottles etc. when discharged.

There is little information about the results of this order but in $182 \mathrm{IMr}$. Garlick paid to the Treasurer $£ 60$ Ios., the amount deposited on bottles.

\section{Admission of Patients}

The admission of patients to the infirmary followed the recommendation of a subscriber and an examination by the physician or surgeon of the week, on a Friday afternoon. In 1776 it was

ordered by the present Annual Board that the House Apothecary shall be permitted to examine the Patients and sign the Recommendations when the Physician and Surgeon shall at any time by business or indisposition be hindered from attending at any Weekly Board.

The apothecary appears to have had a considerable amount of clerical work in addition to his other duties. An advertisement in the Leeds Intelligencer of 6 October 1767 states:

All those who desire to be cut for the Stone, this Season, must send in their Names, Ages and Places of Abode to Mr. Trant, Apothecary to the Infirmary, before the $15^{\text {th }}$ of November next.

And in July 1770 he was ordered, together with the deputy secretary

to correct the Check Book with the Book of patients on Saturday ye 21 instant in the Afternoon and every two months after at least, on some Saturday afternoon in that Month correct all mistakes in the Check Book.

In addition, in March 1783 it was ordered

that the Apothecary lay before the Weekly Board the names of the In Patients that have been upwards of Two Months in the House also that he keep an Account of all that are admitted into the House and are Cured or Dying before their having a Bed in the House and likewise of all who are admitted Out Patients and afterwards received into a Bed in the House. . . . 


\section{The Apothecaries of the General Infirmary at Leeds}

Another duty was imposed on the apothecary in regard to the admission of patients when, in 1797 , it was

Resolved: That ye Apothecary be directed to enquire of all accident Patients when they first present themselves whether they are in a Situation of Life which renders them admissable agreably to the 42 Rule [That no Persons be admitted, who are able to subsist themselves, and pay for their Cure], and that in Case he finds such Persons inadmissable he shall inform them of the Contents of that Rule, and dismiss the Person applying without sending for the Physician or Surgeon of the Week unless the Accident be such that the removal of the Person might endanger his Life, or be of material injury to him.

We find more about the admission of patients in the minutes. The Weekly Board on i I January 1828 noted that

the Infirmary having been of late Years much abused by the application of improper objects of Charity, \& of those whose cases are unsuitable for admission as Patients, such as Bleeding, Toothdrawing \& very trivial Accidents [and it was resolved] That the House Surgeon \& Apothecaries be directed to refuse assistance to all Applicants at the Surgery who are not objects of Charity or proper to be received as Patients.

The apothecary was given fresh responsibilities in 1803 the Board ordering

that the Occupation of the Patients Wards be vested in the Apothecary and that he open a Ward or Wards for the reception of Female Patients immediately.

\section{Professional Work}

We have scant records of the purely professional work of the apothecaries though judging from the minutes this must often have been of high quality. To quote one example, it was in June 1822 ordered

that the thanks of this Board be given to Mr. J. P. Garlick late Apothecary $\mathbb{E}$ House Surgeon to the Leeds Infirmary, who by his professional Skill \& unremitting attention to the interests of the Establishment during a period of seven years, has faithfully discharged the duties of his Office; and who by his experience, humanity, \& conciliating manners, has endeared himself to the patients, and the poor in general; and has thus contributed very materially to support the high character, and usefulness, of this Institution.

A good picture of the surgical practice of the Infirmary at the beginning of the nineteenth century can be built.up from Practical Observations on Surgery $(1803)^{3}$ by William Hey F.R.S. We find occasional references to case-histories such as:

I saw the Patient with Mr. Logan. The wound was then plugged up by pieces of sponge which the House Apothecary had applied, upon an appearance of returning haemorrhage.

A case-notebook of Thomas Turner, probably a senior student, gives a list of some operations watched by him in I823 (Table II). The apothecary is likely to have assisted at these and we thus have some idea of his surgical experience. 


\section{S. T. Anning}

\section{Other Duties}

A variety of other duties was carried out by the apothecary. Thus in 1782 Mr. Peacocke had to give evidence at York Assizes.

The Apothecary of the House being bound over to appear at the Assizes at York to be held next Week as a Witness upon the Trial of Edward Barnett for the Murder of Ambrose Burnside late a Patient of and who died in this House it is Ordered That the Surgeon of the Week appoint a Proper Person to act as Apothecary during Mr. Peacockes Absence.

In 1803 the Board ordered

That the Apothecary have the keeping \& disposal of the Wine and Spirits bought or made for the use of the Patients, [but a week later this was rescinded, it being considered that] the Matron is the most proper Person for the care of those Articles.

The apothecary and the matron were closely associated in their work; as already noted he could never be away in her absence and he had to keep her informed of his whereabouts when he left the House. In 1776 the matron was granted an extra $£ 6$ a year for providing tea and sugar for herself and the apothecary, which was increased to $£ 8$ a year in 1780 'during the present exorbitant Prices of those Articles'. There is no information as to whether they drank this together nor is there evidence that their relationship was any but amicable until May 1803 when at a Board meeting it was reported that

some Differences subsist between the domestic Officers of this Charity which if not investigated may prove injurious thereto [and a committee was appointed to investigate the matter. The committee] upon conferring with Mrs. Wilkinson [the matron] on the subject she exprest her fears of their being able to live together upon a friendly footing ... but that she would take a trial along with Mr. Bennett ... [but upon] the conferring with Mr. Bennett [the apothecary] on the same subject he immediately declared that it was impossible for him to live with the matron upon such a footing as the Board and the interests of the Institution should require and that he should preferably request the Board to accept of his Resignation

which it did.

The duty of the apothecary must at times have been unpleasant as when William Carr was examined by the Weekly Board in 1777 concerning the attendance of Dr. Hird (the senior physician) who had been accused of neglecting the patients. Similarly, it must have been embarrassing for Joseph Prince Garlick to be ordered in 1820 to report the number of times a physician or surgeon failed to attend the infirmary on a Friday afternoon to examine patients for admission. Happily this order was rescinded two months later.

On 26 June 1805 Thomas Parkinson the apothecary was directed 'to procure Quills for the use of the Pupils of the Infirmary' and two days later he resigned, though there is no reason to suppose that it was because of this order.

\section{Duration of Service}

Many of the apothecaries, on appointment, had to give an undertaking to stay three or five years and sometimes the appointment went to the candidate 


\section{The Apothecaries of the General Infirmary at Leeds}

prepared to stay the longest time. Of the twenty-five apothecaries eleven stayed two or three years and six four to seven years. Mr. Allanson (appointed in 1833 ) seems to have been content to make the office his career for he remained no less than nineteen years. The other seven stayed one year or less, some resigning from ill-health.

The shortest period was served by Anthony Dempster who was discharged five weeks after his appointment in January 1774 :

it having appeared to this Board that Mr. Dempster the Apothecary have missbehaved himself to the Female Servants of this House.

There is no evidence that he ever qualified. The son of a York apothecary of the same name, he had in 1764 been apprenticed to a carpenter and cabinet maker in York for seven years but presumably gave that up and became apprenticed to an apothecary though no record has been found of this.

\section{Salary and Gratuities}

It has been mentioned that Mr. Trant's salary in 1767 was $£_{15}$ per annum with board and lodging. This is meagre compared with the $f 80$ a year paid in I 725 to the apothecary at Guy's Hospital' and the $£ 100$ a year with house at St. Bartholomew's in $\mathbf{1 7 4 8 .}$

There was no rise until I 773 when Abel Taylor was appointed with a salary of thirty guineas a year but when, almost a year later, he resigned on account of ill health, the unfortunate Dempster was appointed with a salary of $£ 40$ per annum. His successor (William Cass) started at $£ 30$ which was gradually raised to $£ 40$ by 1776 during which year he also received a gratuity of $£ 5$. The salary continued to vary between $£ 30$ and $£ 40$ (with occasional gratuities of fio) until I8I5 when

the Gentlemen of the Faculty having been requested to consider the best method of serving the Institution in the office of Apothecary

presented a statement of their opinion 'that a considerable Addition should be made to his Salary'. The Board were in agreement and the salary became $£_{1} 100$ per annum with board and lodging and remained at that figure.

\section{Leave of Absence}

No reference to annual and other leave for the apothecaries is made in the Rules and Orders of 1767 and 1786 , though in September of the latter year we find the first mention in the Board minutes of leave when

the Apothecary having askt Mr. Lucas [a surgeon] for leave to be absent on Monday afternoon, \& not having return'd till the Thursday following 


\section{S. T. Anning}

the matter was referred to the consideration of a more numerous Board. A week later:

the Board having taken into Consideration the Minute respecting the Neglect of the Apothecary ... and it appeared that the Apothecary had on a former Occasion Undergone the Censure of the Weekly Board for Impropriety in his Demeanour \& Conversation towards two of the Women patients - and also that the Secretary had omitted to make an Entry of such Censure [it was resolved] that the Secretary be now called in \& Censured . . . [and that] the Conduct of the Apothecary is very highly Blamable_-but that in Consideration of the Apology which he has made to the Board ... \& \& of the Severe Effects which must accrue to him from a Dismission -Resolved that the Board will give him farther Trial of Three Months \& that they will referr any further Decision of this Matter to the Merits of his Conduct during that Period that may be called in.

The apothecary, Joseph Grice, stayed until May 1787.

In 1793 the apothecary, Thomas Rusby, was given five days' leave and the Weekly Board on 7 August I 795 ordered 'that ye Apothecary [Rusby] have Leave of absence for a few days he providing a Substitute'. Leave to attend courses of lectures in London was granted in 1816 and 1824 , as mentioned above, but from 1795 there is no other reference in the minutes to leave of absence until April 1828 when it was noted that:

Mr. Hey, having (on Consultation with the other Gentlemen of the Faculty) represented to the Board that the delicate and critical state of Mr. Farrer's Health, the House Surgeon and Apothecary, rendered it adviseable that he should go into the Country, for the benefit of pure air-Permission allowed.

We do not know for how long he was away though any benefit he derived seems to have been temporary for in August 1829 he resigned in consequence of Indisposition'. Mr. Sharpe had three weeks' leave in $183^{1}$ and two years later he also resigned for the same reason. The impression gained is that the apothecary was not expected to have leave for purely recreational purposes though this view became modified during Mr. Allanson's long tenure of office. Between 1845 and his resignation in $185_{2}$ he had four periods of leave, each of one to three weeks. On one of these occasions (in June 1847):

Mr. Allanson ask'd permission of this Board for three Weeks Absence from his Labours, which having been very arduous for some months, the Board readily granted his request.

\section{The Assistant Apothecaries}

In 18 I3 Mr. Beckett, the apothecary, complained to the Board 'that the Business of the Hospital exceeds his Ability'. There is little doubt that he must have worked hard for there were roo beds and during the year commencing Michaelmas 1812737 patients were admitted. The Board ordered that:

the Gentlemen of the Faculty be requested to consider what method of relief will be most proper ... and that Mr. Roberts be requested to assist in the Interim. 


\section{The Apothecaries of the General Infirmary at Leeds}

The gentlemen of the faculty having reported their opinion 'that an assistant Apothecary will be the most proper mode of relief' the following advertisement was inserted in the Leeds papers for an Assistant Apothecary:

... He must be a Single Man, and one regularly educated to the Profession (and will be considered as acting under the Direction of Mr. Beckett, the present Apothecary) he will also be boarded and lodged in the House, and must be in continual Attendance.

John Brooke Greenwood was appointed.

In course of time it became clear that one assistant provided insufficient help for the apothecary. In the minutes of a Weekly Board meeting held in May I825 we read:

the Faculty having stated to the Board that more assistance was necessary in the Pharmaceutical Department of the House [it was ordered] that the Faculty be requested to make choice of a suitable person to act as second Assistant Apothecary to the House.

There remained two assistant apothecaries until 1860 when the title of the appointment was changed.

All the assistant apothecaries were unqualified on appointment but had served their apprenticeship with a surgeon or apothecary. The fee paid for the apprenticeship varied. In 1830, when James Paget ${ }^{6}$ was bound to Mr. Charles Costerton of Yarmouth, his father had to pay a hundred guineas but William Carwithen Ford of Kingsbridge in Devon was paid $£ 252$ ros. od. for taking Richard Paige Tucker as apprentice, for which he had to provide 'good and sufficient meat, drink and lodgings' and instruct him in the profession and practice of a surgeon and apothecary. ${ }^{7}$

Living under the same roof, as was customary in the days of medical apprenticeship, the preceptor could look after both mind and morals of his pupil. The fledgling, in return for the instruction received at the hands of his master, not only compensated him for his trouble, but performed many of the menial offices of a servant about the house and the office. It was he who prepared the powders, mixed concoctions, made the pills, swept the office, kept the bottles clean, assisted in operations, and often through main force supplied the place of the anaesthetic of today in the amputation of limbs and other surgical procedures. He rode about with the doctor from house to house, profiting by his personal experience. . . . ${ }^{8}$

The advertisement for an assistant apothecary inserted in the papers in June I856 states that

The Situation is very eligible for Young Gentlemen who have served a regular Apprenticeship to the Profession of a Surgeon, as they will be Free of the Practice of the Hospital, with Board, Washing and Lodging. No pecuniary Emolument is allowed.

We only know the age on appointment of one of the assistant apothecaries, namely, Charles Elam who was 20 years old.

Many of the assistant apothecaries qualified within a few years of resigning their appointment though six of the thirty-one never did so. The usual period of service in this office was two years though three served only about one year. 


\section{S. T. Anning}

Two served three years, four four years, two for five and C. F. Brown for as long as six years, an early example of the 'chronic' student one imagines. He qualified however in 1840, a year after resigning. From 1832 all but two of the assistant apothecaries qualified, most with a double qualification (medical and surgical) and one (Charles Elam) became F.R.C.P.

The Apothecaries' Act became law in 1815 and in August of that year the Court of Examiners of the Worshipful Society of Apothecaries laid down the first detailed regulations. Candidates were expected to possess a competent knowledge of Latin (to understand prescriptions); to produce certificates of having attended two courses of lectures on anatomy and physiology, two on the theory and practice of medicine, one on chemistry and one on materia medica; of six months' attendance on the practice of a public hospital, infirmary or dispensary; and of five years' apprenticeship to an apothecary. The examination intended after this curriculum was by vioa voce only, as was customary at that time. ${ }^{9}$ The candidate was not admitted unless 21 years of age.

From 1800 the usual qualification for a surgeon was Membership of the Royal College of Surgeons, the London College requiring as education for this examination no more than certificates of one course on anatomy and one on surgery. In 1813 the College added a year's attendance on the surgical practice in a hospital, namely, walking the surgical wards and attending operations: there was no need in London to learn any medicine at all. A general practitioner should have passed the examination of the Apothecaries' Hall and between 1818 and 1841 there were seven ex-assistant apothecaries who went into practice with this qualification. In fact this was not essential and a surgical diploma, obtained without learning any medicine, could be used as a qualification for general practice. ${ }^{9}$ Several of the apothecaries and assistant apothecaries between 1804 and 1854 had only the M.R.C.S. as qualification. E. W. Ward (1854) was the last.

It must have been difficult for the earlier assistant apothecaries and the pupils to attend courses in anatomy and physiology without going to London. Some courses were given in Leeds but only irregularly. In 1773 the Weekly Board ordered:

that the Surgeons of this Charity be desired to lay ... an Acct. of the Expences incurred by the Procurement of the Body from York lately dissected at this Infirmary.

And in 1803,1805 and 1808 William Hey, F.R.S. (the senior surgeon) gave public anatomical demonstrations which raised $£ 47$ i rs. $6 d$. on the first occasion. In 1805 the Board noted that the skeleton requires considerable repairs. Mary Bateman, 'the Yorkshire witch', was tried in 1808 for murder and convicted. She pleaded pregnancy, was found 'not enceinte' and was executed at York, her body being given for dissection to the surgeons of the Leeds Infirmary.

There seems little doubt that the training of medical students was neglected. Dissatisfaction was widespread and some was ventilated in correspondence in the Lancet of I 824. It was considered that the surgeons, who accepted large fees 


\section{The Apothecaries of the General Infirmary at Leeds}

from their pupils, were not carrying out their obligation of instructing them. Sir Astley Cooper of Guy's Hospital was an exception. The pupil's fees were heavy and some students, such as James Paget, could not afford them and picked up what information they could in the wards. The physicians also came in for some criticism.

Robert Baker, M.R.C.S., in his Remarks on the Abuses in the Infirmary [at Leeds] (1827) mentions that:

heavy apprentice fees are obtained, and the receipts from all the young men who are entered as Hospital Pupils, are appropriated to them

(i.e. the surgeons). But the main abuse was that Baker had not been appointed a surgeon. ${ }^{10}$

The first attempt at regular instruction in anatomy in Leeds was made by Charles Turner Thackrah (famous for his book The Effects of Arts, Trades and Professions ... on Health and Longevity). He first restricted his teaching to his six apprentices but early in 1826 established a private school of anatomy at 9, South Parade, Leeds. He hoped that attendance at his lectures and the practice of dissection in his school would be admitted by the Royal College of Surgeons, but the Court of Examiners refused his application in 1826 and others made until $1831 .{ }^{11}$

Unfortunately there was friction between the senior members of the profession on the staff of the infirmary and others, mainly apothecaries, led by Thackrah and his pupils. There was a crisis in 1827 at a teaching given by Mr. Samuel Smith, senior surgeon to the infirmary. An altercation arose between the supporters of the two parties. One of Thackrah's pupils, Richard George Horton (later a general practitioner in Leeds) produced a horse-whip with which he thrashed Willson Cryer, the senior assistant apothecary. He was prosecuted and fined $£ 20$ for this assault. Mr. Cryer qualified L.S.A. in 1830 and in 1847 was practising in Bradford.

An opinion was arising that there should be a medical school in Leeds. Several provincial medical schools had been established-at Bristol in 1818, at Manchester in 1824 and at Sheffield in 1828 . Thackrah was most active in prosecuting the idea probably because his private school had never become recognized by the College of Surgeons and, moreover, he and Samuel Smith appear to have become reconciled. They and a group of medical men which included Joseph Prince Garlick (a former apothecary of the infirmary) and William Hey (the third) founded the Leeds School of Medicine in 1831. In the following year the Weekly Board of the Infirmary:

resolved unanimously, that the present and future senior Assistant Apothecary of this Institution be allowed to attend the Lectures of the Leeds School of Medicine.

\section{The Title Changed}

It was ordered by the Board in February 1860 that the term 'Resident Medical Officer' should be substituted for 'Apothecary' and the change applied 


\section{S. T. Anning}

to the assistants also. From 1826 the apothecary had occasionally been referred to as the house surgeon and commonly so in the 1850 's. At St. Bartholomew's hospital house surgeons were mentioned as early as $1813 .{ }^{5}$ In 1835 a housesurgeoncy at that hospital was expensive and beyond James Paget's means ${ }^{6}$ though at Guy's hospital in 1856 it was a six months' appointment for students chosen after they had obtained the diploma of the Royal College of Surgeons. ${ }^{4}$ It was not until I867, however, that at St. Bartholomew's the office of apothecary was abolished and four house physicians appointed, each paid $£ 25$ a year.

\section{The Later Careers of the Apothecaries}

Of the twenty-five apothecaries it has only been possible to trace the careers of sixteen. Some never qualified and some died early. William Thomas Trant, as noted, became a druggist in Leeds; nine apothecaries went into general practice in Leeds or elsewhere and one, Robert Hardcastle, died soon after resigning the appointment. Samuel Hare became a surgeon in Leeds and later in London and J. P. Garlick surgeon to the Leeds Public Dispensary. Anthony Cass was a candidate for the office of surgeon to the infirmary and was a surgeon in Leeds in 1826 . The only one to get on the honorary staff of the infirmary was Robert George Hardwick who was appointed physician in 1860. The first resident medical officer, T. R. Jessop, appointed in 1860 , became honorary surgeon ten years later.

The majority of the assistant apothecaries went into general practiceeighteen of the thirty-one-most in Yorkshire though one in Clapham Common. Charles Elam became a physician in Harley Street and Thomas Churton was appointed physician to the infirmary in 1880 . Thomas Scattergood, having been lecturer in chemistry for many years in the Leeds School of Medicine became surgeon to the Hospital for Women and Children in 1863 and he was Dean of the Medical School. The other ten have not been traced.

\section{Summary}

The qualifications, duties and later careers of some of the apothecaries and assistant apothecaries of the General Infirmary at Leeds have been traced. An apothecary might become a druggist, apothecary or general practitioner, physician or surgeon.

\section{ACKNOWLEDGMENTS}

I am grateful to Sir George Martin, Chairman, and the Board of Governors of the United Leeds Hospitals for allowing me access to the Weekly and Quarterly Board Minutes and to other documents, without which this work would have been impossible.

I am especially indebted to a number of librarians: A. H. Hall, of the Guildhall Library, London, W. R. Le Fanu of the Royal College of Surgeons of London, Miss Frances S. Brown of the Royal College of Surgeons of Edinburgh, O. S. Tomlinson of the Public Library, York, and F. N. L. Poynter of the Wellcome Historical Library where I have consulted the Medical Registers of 1779,1780 and 1783 and the early Medical Directories. I am also grateful to the 


\section{The Apothecaries of the General Infirmary at Leeds}

Clerk of the Worshipful Society of Apothecaries of London for his help, and to Sir Linton Andrews, Editor of the Yorkshire Post, for allowing me to refer to the Leeds Intelligencer, and to the Librarian of the Leeds Reference Library for access to Leeds Directories (1790 to 1860).

Mr. A. H. Boyes kindly let me reproduce his engraving of the Infirmary; Dr. G. W. C. Johnson gave me the apothecary's bed ticket; and Dr. J. M. A. Critchley lent me the student's notebook.

\section{REFERENCES}

I. Bishop, W. J. 'The Evolution of the General Practitioner in England.' Practitioner, 1952, cLXviI, 171.

2. Rules and Orders of the General Infirmary at Leeds. Leeds, 1767.

3. Hey, William. Practical Observations on Surgery. London, 1803.

4. Wilks, Samuel and Bett any, G. T. A Biographical History of Guy's Hospital. London, 1892.

5. MoOre, Norman. The History of St. Bartholomew's Hospital. II. London, 1918.

6. Paget, Ste Phen. Memoirs and Letters of Sir James Paget. London, 1903.

7. McConaghey, R. M. S. Notes on the Evolution of Medical Practice prior to 1858 . F. Coll. gen. Pract., 1958, 1, 267.

8 MYER, J. S. The Life and Letters of Dr. William Beaumont. London, 1939.

9 Newman, Gharles. The Evolution of Medical Education in the Nineteenth Century. London, 1957.

10. BAKER, ROBERT. Remarks on the Abuses in the Infirmary. Leeds, 1827.

11. Meiklejohn, A. Charles Turner Thackrah. Edinburgh and London, 1957. 


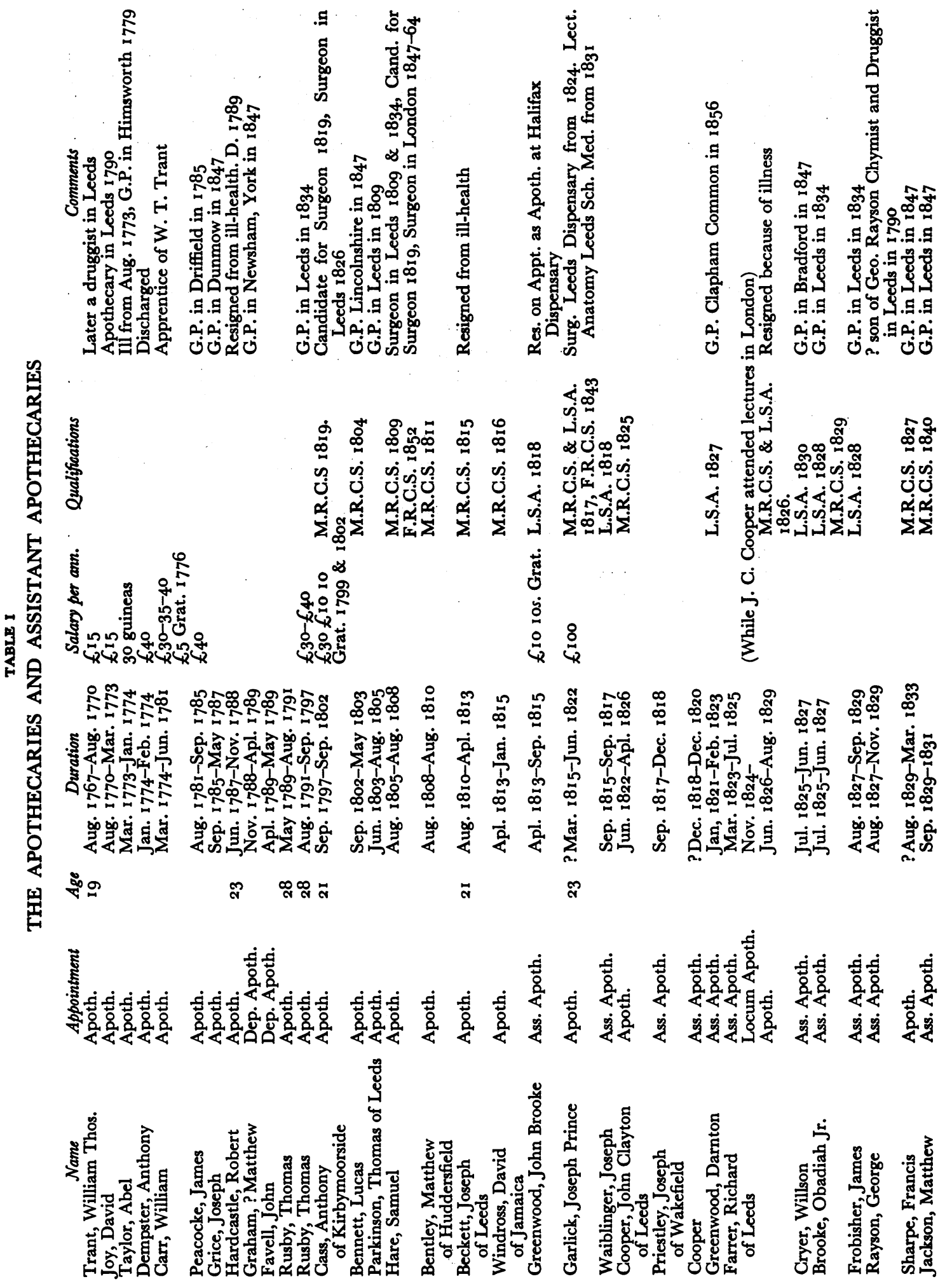




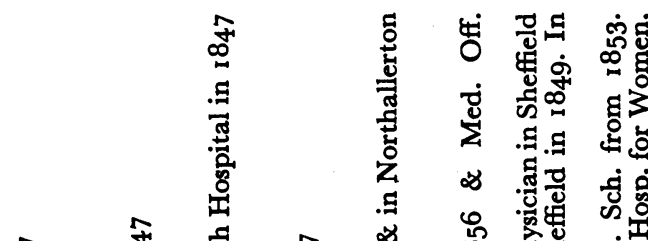

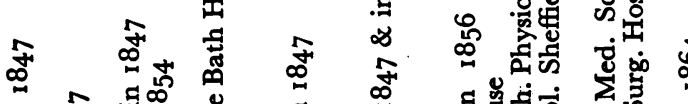

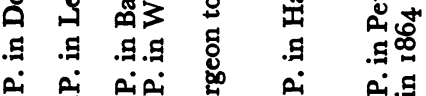

نे t⿹丁口

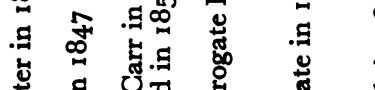

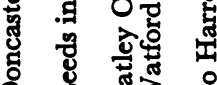

品尊.

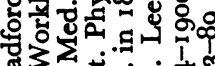

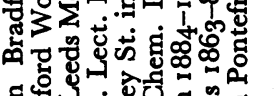

ơ

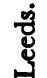

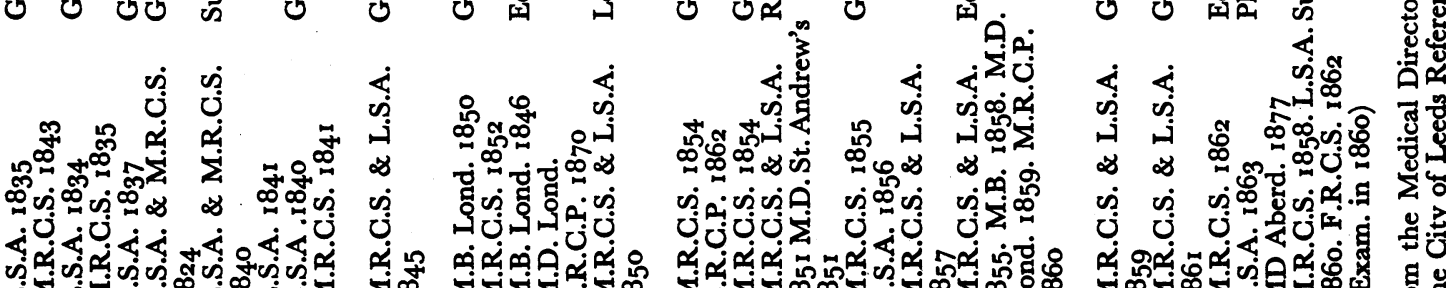

온
蛋

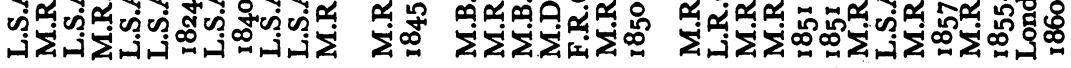

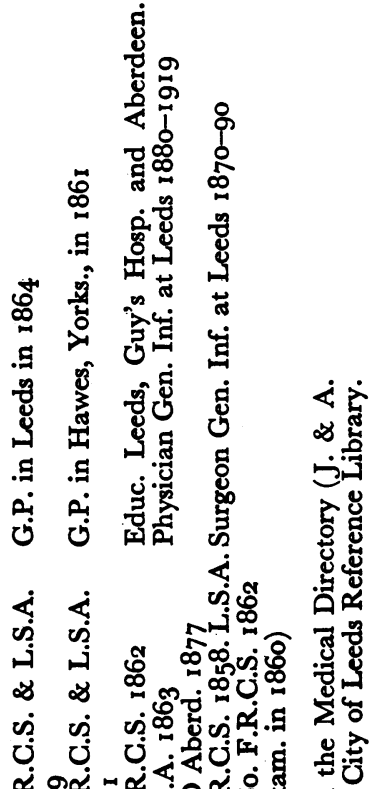

$\tau \cdot 9$

递定

$\therefore$ 居

중 .

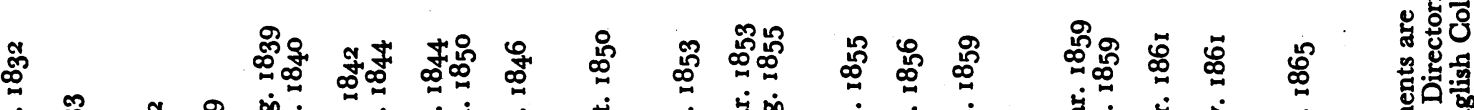

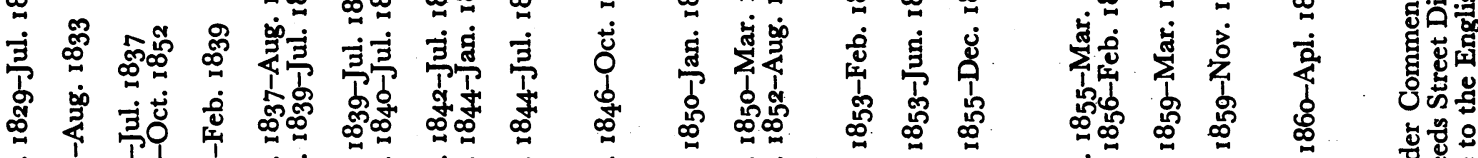

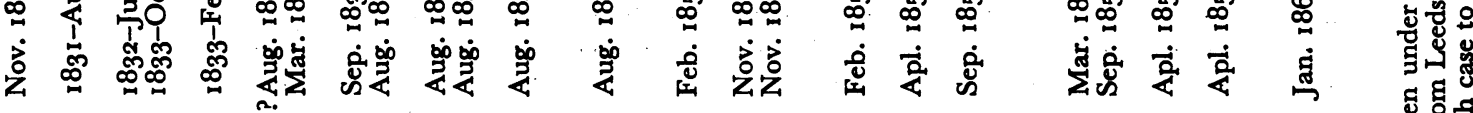
\& 8

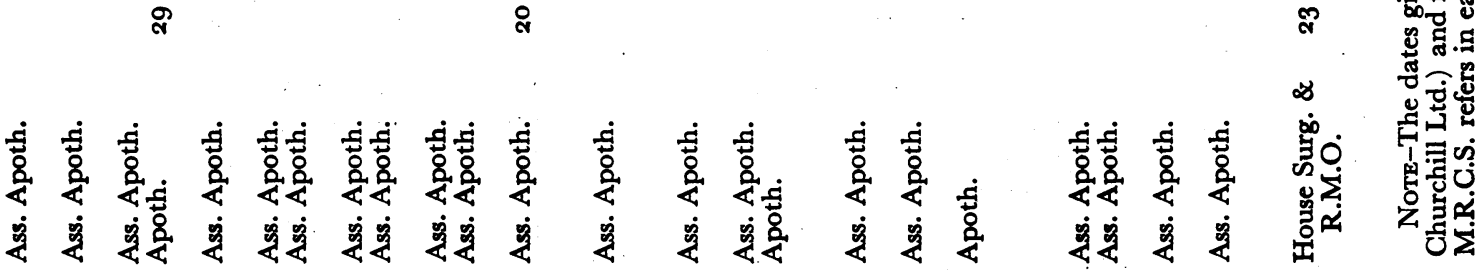

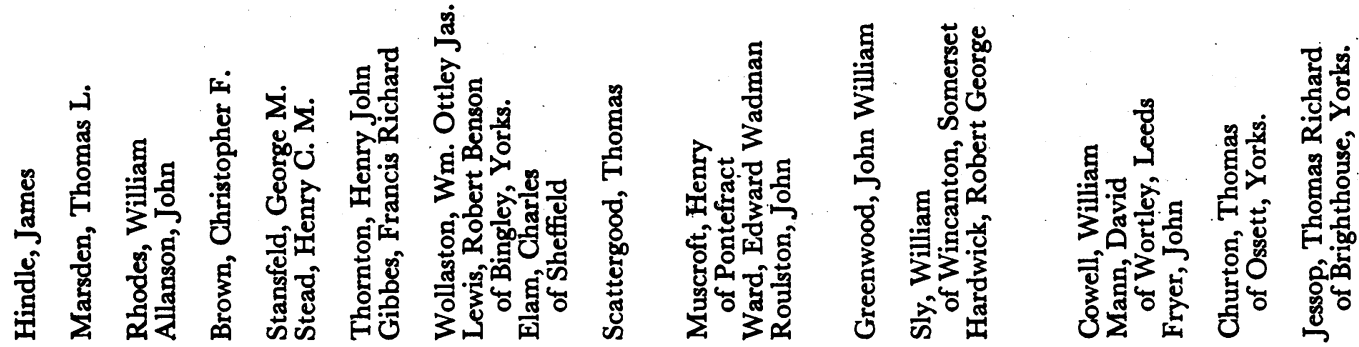


TABLE II

\section{A SERIES OF OPERATIONS WATCHED BY A STUDENT IN 1823}

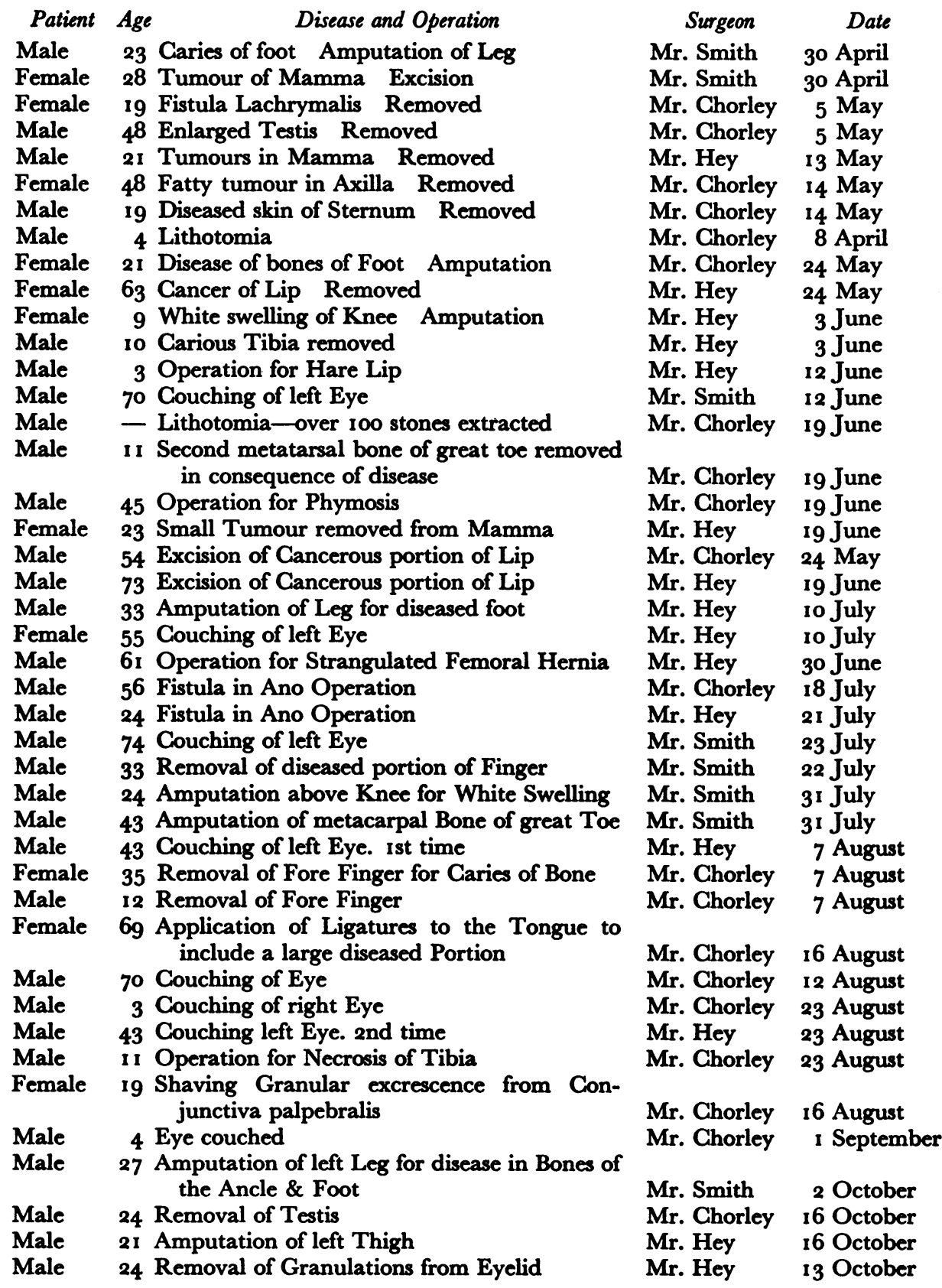

